\title{
Differentiation and Maturation of Embryonal Carcinoma-Derived Neurons in Cell Culture
}

\author{
Michael W. McBurney, ${ }^{1}$ Kenneth R. Reuhl, ${ }^{2}$ Ariff I. Ally, ${ }^{3}$ Soma Nasipuri, ${ }^{1}$ John C. Bell, ${ }^{1}$ and Jane Craig ${ }^{1}$ \\ 'Departments of Medicine and Biology, University of Ottawa, Ottawa, Canada K1H 8M5, and ${ }^{2} E$ cotoxicology Group and \\ ${ }^{3}$ Medical Biosciences, National Research Council of Canada, Ottawa, Canada K1A OR6
}

\begin{abstract}
We have previously shown that retinoic acid-treated cultures of the P19 line of embryonal carcinoma cells differentiate into neurons, glia, and fibroblast-like cells (Jones-Villeneuve et al., 1982). We report here that the monoclonal antibody HNK-1 reacts with the neurons at a very early stage of their differentiation and is, therefore, an early marker of the neuronal lineage. Cells in differentiated P19 cultures synthesized acetylcholine but not catecholamines, suggesting that at least some of the neurons are cholinergic. The neurons also carry high-affinity uptake sites for GABA but not for serotonin. In long-term cultures, neuronal processes differentiated into axons and dendrites, which formed synapses. This biological system should prove valuable for examining the development and maturation of cholinergic neurons, since their differentiation occurs in cell culture.
\end{abstract}

In vertebrates the development of mature functional neurons from pluripotential embryonic cells occurs by a multistep process. Cclls with ncuronal characteristics develop from their precursors as a result of both inductive and lineage events (Jacobson, 1985). Subsequent to their neuronal differentiation, for which the appearance of neurofilaments appears to be a reliable early lineage marker (Cochard and Paulin, 1984), cells remain plastic and can alter the neurotransmitter they synthesize depending upon other environmental cues, such as soluble factors (Patterson, 1978) or cellular location (Coulombe and BronnerFraser, 1986; Park et al., 1986).

One approach towards analyzing the events involved in the development of neurons and their subsequent maturation has been to explant neurons or their precursor cells into culture under conditions in which exposure to soluble factors and interactions with other cells can be controlled. The major difficulties with this approach are that the amount of material is limited by the size of the embryonic tissue used for explantation and that cell types are often mixed and develop asynchronously. Some of these disadvantages may be overcome with a biological system derived from mouse teratocarcinomas.

We have described the differentiation of P19 cells, a clonal

Received May 29, 1987; revised July 24, 1987; accepted Aug. 26, 1987.

We thank Drs. E. Georges and W. Mushynski for rabbit antibody to the 68 $\mathrm{kDa}$ neurofilament protein, Dr. P. Walker for nerve growth factor, and Dr. David Gottlieb for GAD activity measurements and GAD-1 antibody. This work was supported by grants from the National Cancer Institute of Canada. M.W.McB. is a Terry Fox Research Scientist of the NCIC

Correspondence should be addressed to Michael W. McBurney, Department of Medicine, University of Ottawa, 451 Smyth Road, Ottawa, Canada K1H 8M5.

Copyright (C) 1988 Society for Neuroscience $0270-6474 / 88 / 031063-11 \$ 02.00 / 0$ line of mouse embryonal carcinoma (EC) cells. When induced to differentiate with retinoic acid (RA), these cells develop in a manncr closely resembling that of embryonic brain tissue; that is, cells differentiate into neurons, glia, and fibroblast-like cells (Jones-Villeneuve et al., 1982, 1983). The neurons become abundant in these cultures by 5-6 d after RA treatment and appear to be a homogenous population of small, postmitotic cells with long branching processes. The neurons may be obtained almost free of glial and fibroblast cells with the use of serum-free medium or drugs cytotoxic to growing cells (Rudnicki and McBurney, 1987). The neurons contain neurofilaments and their surfaces bind tetanus toxin (Jones-Villeneuve et al., 1982, 1983). RA-treated cultures of P19 cells also contain high levels of CAT and AChE, suggesting that at least some of the neurons may be cholinergic. In addition, these cultures contain the neuron-specific protein product of the c-src oncogene (Lynch et al., 1986) along with gangliosides characteristic of neurons (Levine and Flynn, 1986).

When implanted into mouse embryos, EC cells can contribute to the development of normal embryos (Papaioannou, 1979), suggesting that the mechanisms of differentiation of EC cells are similar to those of normal embryonic cells. Differentiating cultures of P19 cells may, therefore, be an appropriate biological system for the study of some of the early events of neuronal development and differentiation because the P19-derived neurons can be obtaincd in culture in unlimited quantity and can be produced from EC cells carrying mutations or transfected genes (Edwards et al., 1983; Jones-Villeneuve et al., 1983; Bell et al., 1986). We set out to more fully characterize the P19derived neurons by identifying early markers of their neuronal differentiation and by determining whether they have biochemical properties consistent with their ability to synthesize and respond to chemical neurotransmitters. The evidence reported below suggests that at least some of the P19-derived neurons are cholinergic and that they can mature in culture to form synapses.

\section{Materials and Methods}

Cell culture conditions. For the experiments described below, we used the P19 line of EC cells (McBurney and Rogers, 1982) or a clonal derivative called P19S1801A1 (McBurney et al., 1982). Cells were cultured and induced to differentiate as described by Rudnicki and McBurney (1987).

To treat cells with RA, cultures of P19 cells were normally aggregated by plating them into bacterial-grade petri dishes in the presence of $3 \times$ $10^{-7}$ M RA (Jones-Villeneuve et al., 1982). After $4 \mathrm{~d}$ of incubation, the drug was removed and the aggregates were plated onto tissue culturegrade surfaces or gelatin-coated coverslips. In those experiments involving assays of cells exposed to RA for between 0 and $4 \mathrm{~d}$ the aggre- 
gation step was omitted and cells were cultured directly on the coverslips during the RA exposure.

Immunofluorescence. For immunofluorescent detection of the cellsurface antigens recognized by the monoclonal antibodies A2B 5 and HNK-1, live cells either grown on coverslips or attached to coverslips with poly-L-lysine (Rudnicki and McBurney, 1987) were washed with PBS containing 5\% calf serum, incubated for $45 \mathrm{~min}$ in culture supernatant containing the antibody, washed 3 times in PBS for $5 \mathrm{~min}$, incubated for $45 \mathrm{~min}$ in fluorescein isothiocyanate (FITC)-labeled rabbit anti-mouse immunoglobulin, washed again, fixed in methanol at $-20^{\circ} \mathrm{C}$ for 5 min, dried, and mounted.

For staining with antibodies NF68, NF160, and SY38, cells were first fixed in $-20^{\circ} \mathrm{C}$ methanol for $5 \mathrm{~min}$, dried, hydrated in PBS, and stained as above.

In double-labeling experiments involving both HNK-1 and NF68 or NF160, staining was sequential, as described above, except that classspecific secondary antibodies conjugated to either FITC or tetramethylrhodamine isothiocyanate (TRITC) were used to distinguish the locations of the 2 primary antibodies.

In some experiments, cultures were dissociated in PBS containing 1 mM EDTA and the cells allowed to attach to poly-L-lysine-coated coverslips before staining. This procedure was used when the proportion of labeled cells was to be determined.

The A2B5- and HNK-1-secreting cell lines were purchased from ATCC (Rockville, MD). The NF68, NF160, and SY38 antibodies were purchased from Boehringer-Mannheim (Dorval, Quebec)

Neurotransmitter detection. For detection of catecholamines, cells were extracted by sonication in cold $0.4 \mathrm{M}$ perchloric acid containing 0.5 $\mathrm{g} /$ liter sodium metabisulfite and $0.7 \mathrm{~g} /$ /iter EDTA. The sonicate was centrifuged $(11,000 \times g$ for $5 \mathrm{~min})$ and the excess perchlorate in the supernatant precipitated with potassium hydroxide. The filtered supernatant $(0.2 \mu \mathrm{m})$ was injected directly into the high-performance liquid chromatography (HPLC) column. Separation was on a biophase reversephase $\mathrm{C}-18,5 \mu \mathrm{m}, 250 \times 4 \mathrm{~mm}$ column (Bioanalytical Systems, W. Lafayette, IN). The chromatographic separation was at ambient temperature, using a solvent mixture of $1 \times 10^{-6} \mathrm{M}$ octane sulfonic acid (Eastman Kodak, Rochester, NY) in $0.15 \mathrm{~m}$ chloroacetic acid (Fisher Scientific, Ottawa, Ontario) containing $2.5 \mathrm{mM}$ EDTA (pH 3.0) at a flow rate of $1 \mathrm{ml} / \mathrm{min}$. The catecholamines norepinephrine and epinephrine were detected by electrochemical oxidation at a potential of $0.7 \mathrm{~V}$ versus $\mathrm{Ag} / \mathrm{AgCl}$ reference in a TL-5 flow cell coupled to a LC-4-B electrometcr (Bioanalytical Systems). In those analyses in which samples were also monitored for dopamine, 5-hydroxyindole acetic acid (5-HIAA) and 5-HT, the buffer composition was modified as described in Ally et al. (1986). For samples derived from cells preincubated with ${ }^{3} \mathrm{H}$-tyrosine (Amersham International, Amersham, UK), peak fractions corresponding to unlabeled standards were collected and counted in a Beckman LS100 liquid-scintillation counter.

To detect $\mathrm{ACh}$, cells were washed in ice-cold phosphate buffer and rapidly extracted in $100 \mu \mathrm{l}$ ice-cold $0.4 \mathrm{M}$ perchloric acid with sonication, followed by 2 freeze-thaw cycles. The cell debris was pelleted by centrifugation $(10,000 \times g)$. The supernatant was transferred to a second microtube and perchlorate ions precipitated by the addition of potassium acetate. The filtered supernatant was injected onto a Nova-pak G-18 cartridge (Waters Associates, Toronto, Ontario) using a mobilc phase essentially as described in Bymaster et al. (1985), with the omission of the post-column enzyme mixture reactor for amperometric detection of choline oxidase-generated hydrogen peroxide. Instead the ${ }^{3} \mathrm{H}-$ choline (Amersham) and ${ }^{3} \mathrm{H}$-ACh peaks were collected and counted in a Beckman LS-100 liquid-scintillation spectrometer.

The HPLC system consisted of a LKB 1250 dual-piston, DC-drive pump (Fisher Scientific), a U6K injector (Waters), an electrochemical detector with a glassy carbon working electrode (LC-4B; Bioanalytical Systems), a LKB fraction collector (Fisher Scientific), and a M480 controller (Waters).

Electron microscopy. Aggregates of RA-treated P19 cells were fixed in $1.0 \%$ glutaraldehyde in $0.1 \mathrm{M}$ phosphate buffer $(\mathrm{pH} 7.38)$ for $30 \mathrm{~min}$. Samples were gently centrifuged to form a loose pellet, and the medium replaced with $3.0 \%$ glutaraldchydc in $0.1 \mathrm{M}$ phosphatc buffer for $2 \mathrm{hr}$. After fixation, aggregates were washed in buffer, postfixed in $1 \%$ osmium tetroxide for $90 \mathrm{~min}$, dehydrated in ascending concentrations of ethanol and acetone, and embedded in Epon-Araldite. Semithin sections were stained with toluidine blue for light-microscopic assessment. Thin sections $(60 \mathrm{~nm})$ were cut on a Reichert Ultracut microtome, stained with uranyl acetate and lead citrate, and examined with a Zeiss $10 \mathrm{C}$ electron microscope.

\section{Results}

\section{Neuronal cell markers}

A few cell-surface antigens have been identified on neuronal cells and we have examined the P19-derived neurons for the presence of 2 of them, A2B5 and HNK-1.

A2B5 (Eisenbarth et al., 1979) is a monoclonal antibody that reacts with a polysialoganglioside (Kasai and $\mathrm{Yu}, 1983$ ). This antigen is present on most neurons (Schnitzer and Schachner, 1982), but is also present on non-neuronal derivatives of the neural crest (Eisenbarth et al., 1982) and on the astroglial and oligodendrocyte precursor cells (Raff et al., 1983). Most, but not all, cells with processes in the RA-treated P19 cultures stained with the A2B 5 antibody (Fig. 1, $a, b$ ). The intensity of staining of these cells with neuronal morphology was variable, and a small proportion of cells with non-neuronal morphology were also stained.

The A2B5 antibody also stained some of the P19 cells in exponentially growing, morphologically undifferentiated EC cell populations that had never been exposed to RA. The intensity of staining with A2B5 was variable, with $10-15 \%$ of the cells showing some positive reaction to the antibody. This same proportion of A2B5-positive cells was present in a clonal derivative of the P19 cell cultures. Cultures of EC cells stained with both A2B5 and SSEA-1 (Solter and Knowles, 1978), an antibody thought to react exclusively with EC cells, indicated that approximately $85 \%$ of cells were SSEA $1+/ \mathrm{A} 2 \mathrm{~B} 5-, 10 \%$ were $\mathrm{SSEA} 1+/ \mathrm{A} 2 \mathrm{~B} 5+$, and $5 \%$ were SSEA $1-/ \mathrm{A} 2 \mathrm{~B} 5+$.

The monoclonal antibody HNK-1 reacts with glycoproteins present on natural killer cells (Abo and Balch, 1981), on Schwann cells and oligodendrocytes (McGarry et al., 1983; Schuller-Petrovic et al., 1983), and on embryonic neurons (Tucker et al., 1984; Vincent and Thiery, 1984). Virtually all cells in RAtreated P19 cultures with neuronal morphology reacted with HNK-1 (Fig. 1, $c, d$ ). The intensity of staining was not as variable as for A2B5. Undifferentiated EC cells were not stained with HNK-1. The first HNK-1-positive cells appeared in P19 cultures $3 \mathrm{~d}$ after the addition of RA. On day 4 , neuronal processes appeared on some cells and these were all HNK-1-positive. All process-bearing cells stained until at least day 10 , and the intensity of staining did not change noticcably with the age of the neurons.

The HNK-1 antigen appears to be a useful early marker for detecting neurons in RA-treated P19 cell cultures. To prove that the HNK-1 antigen was present exclusively on neurons, we performed double-labeling experiments with HNK-1 and either NF68 or NF160, monoclonal antibodies that react with the 68 and $160 \mathrm{kDa}$ neurofilament proteins, respectively. The 68 and $160 \mathrm{kDa}$ neurofilament proteins appear very early during neuronal differentiation and are present in virtually all neurons (Tapscott et al., 1981; Cochard and Paulin, 1984). Both NF68and NF160-reactive cells initially appeared on day 3. Soon after RA treatment, on days 4-6, the NF160 antibody reacted more strongly and with more cells than did the NF68 antibody; for example, on day 5, approximately $90 \%$ of HNK-1-positive cells were also NF160-positive, while $10 \%$ were HNK-1-positive and NF68-negative (Fig. 2, $a-c$ ). Very rarely were NF160-positive cells HNK-1-negative. By day 10 the intensity of NF160 staining had decreased, leaving approximately $60 \%$ of $\mathrm{HNK}-1$-positive cells also NF160-positive.

At early stages, the NF68 antibody stained fewer neurons than did HNK-1. On day 5 only $60 \%$ of HNK-1-positive cells were also NF68-positive. This proportion increased with time until, 

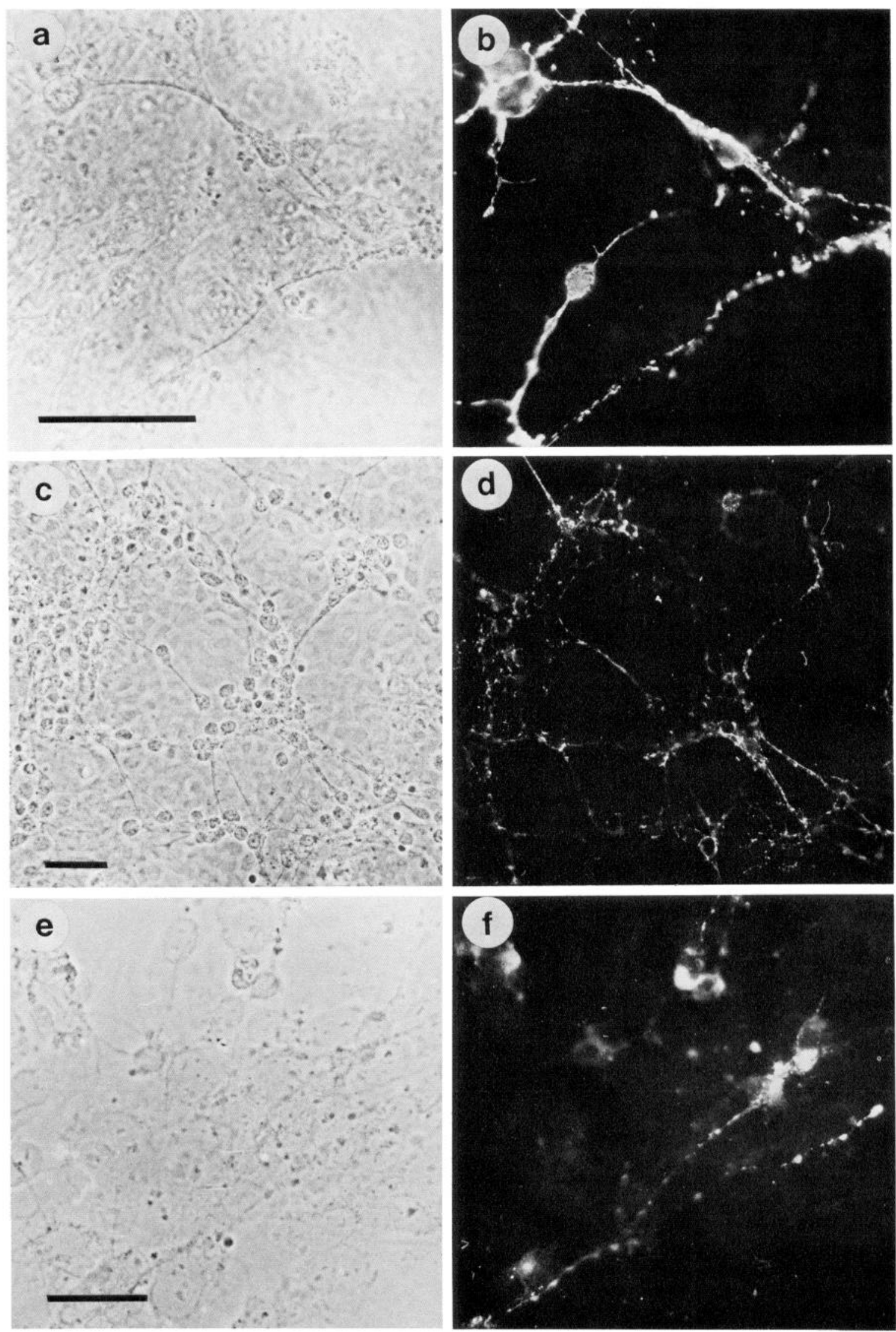

Figure 1. Cells in RA-treated P19 cultures express neuron-specific markers on their plasma membranes. Aggregates of P19 cells were maintained in suspension for $4 \mathrm{~d}$ in $3 \times 10^{-7} \mathrm{M}$ RA, plated onto glass coverslips, and incubated for an additional 3-4 d. Cultures were then washed with PBS, prepared for immunofluorescence with monoclonal antibodies A2B5 $(a, b), \mathrm{HNK}-1(c, d)$, or SY38 $(e, f)$. The photographs in $a, c$, and $e$ show the phase-contrast area corresponding to the fluorescent photographs in $b, d$, and $f$, respectively. Magnification bars, $50 \mu \mathrm{m}$. 



Figure 2. The cells stained with HNK-1 also contain neurofilaments. Cultures of RA-treated P19 cells were stained with the HNK-1 antibody, fixed in $-20^{\circ} \mathrm{C}$ methanol, and subsequently stained with NF68 or NF160. The phase-contrast photograph $(a)$ represents the same area shown in $b$ stained with NF68, and in $c$ stained with HNK-1. Similarly, $d$ shows the phase-contrast of the area stained with NF160 in $e$ and with HNK-1 in $f$. Magnification bars, $50 \mu \mathrm{m}$. 

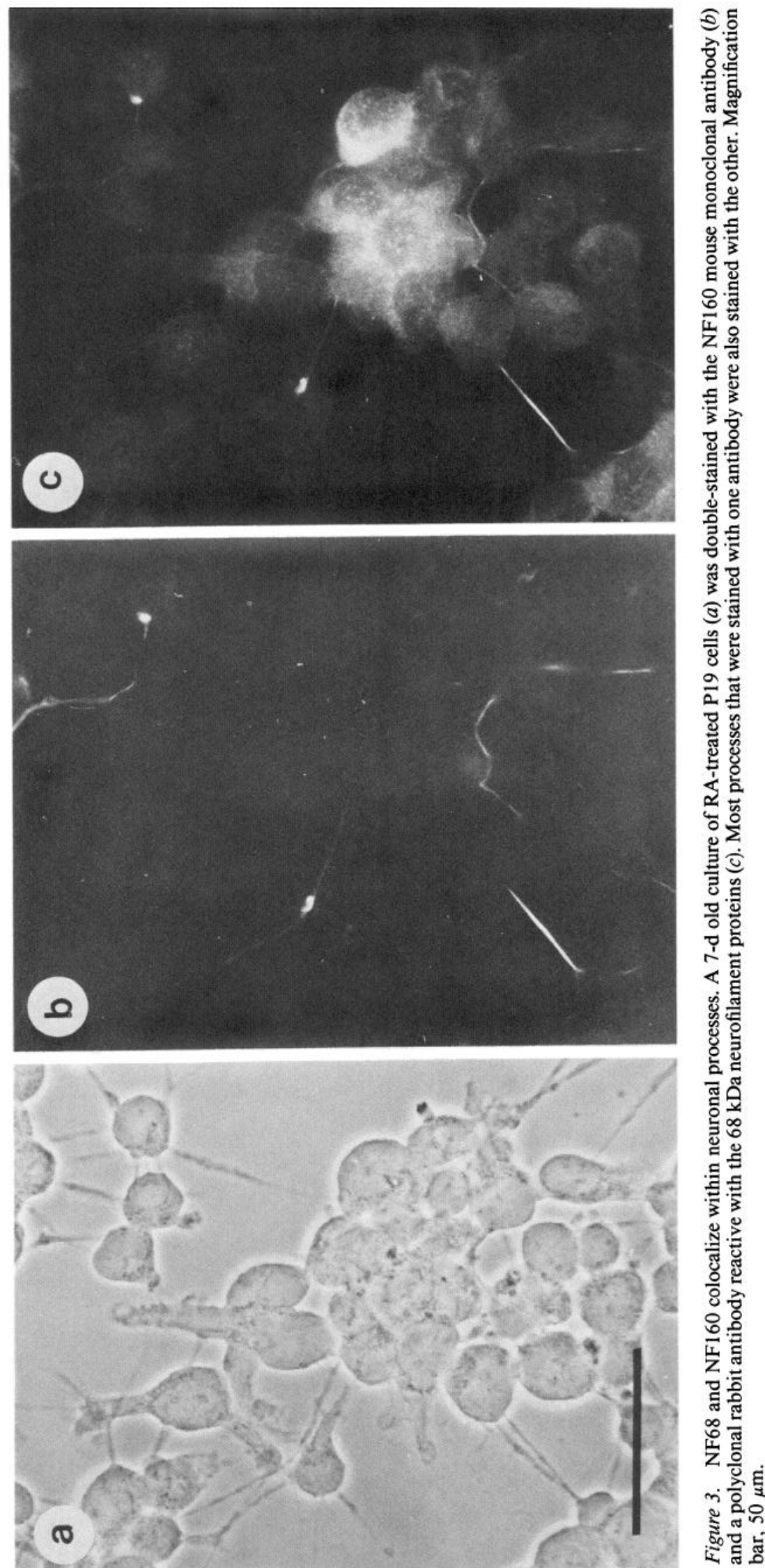

究它 

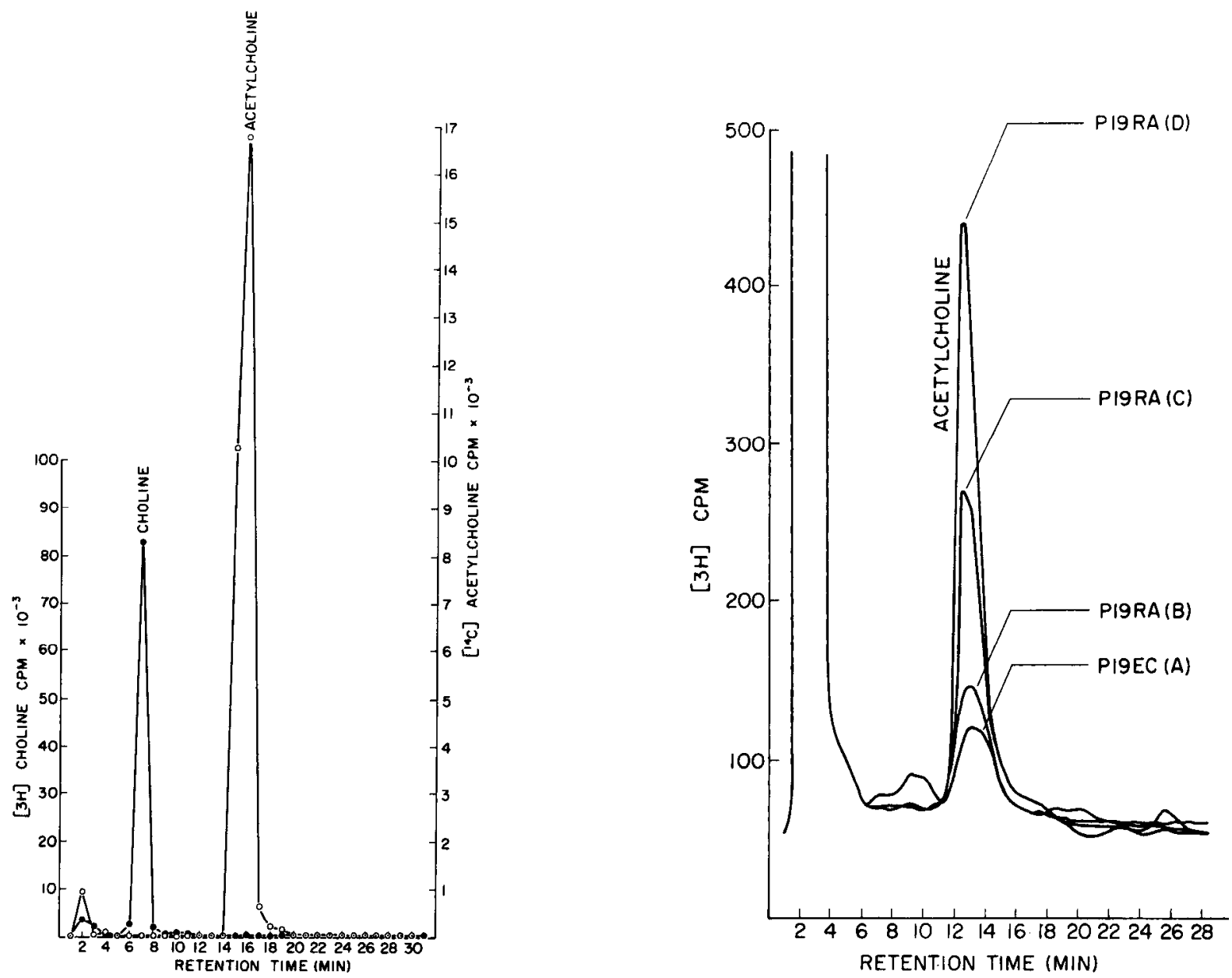

Figure 4. RA-treated P19 cultures contain cells that synthesize acetylcholine. Cultures of EC- or RA-treated P19 cells were incubated for up to $11 \mathrm{~d}$ before being washed and incubated for $2 \mathrm{~h}$ in medium containing ${ }^{3} \mathrm{H}$-choline. Cultures were then washed, and an extract prepared. Each extract was run on the HPLC column described in Materials and Methods and fractions collected for scintillation counting. Left, the separation of ${ }^{3} \mathrm{H}$-choline from ${ }^{14} \mathrm{C}$-ACh. Right, ${ }^{3} \mathrm{H}$-ACh synthesized by $\mathrm{P} 19$ cells incubated for $0 \mathrm{~d}(A), 7 \mathrm{~d}(B)$, and $11 \mathrm{~d}(C, D)$ following RA exposure. Traces $A-C$ came from one experiment and the sample shown in $D$ came from another.

by day $10,90 \%$ of HNK-1-positive cells were also NF68-positive (Fig. 2, $d-f$ ).

The above results suggest that HNK-1 reacted with all neurons and that NF68 and NF160 reacted with only a subset of neurons. It is generally believed that NF68 and NF160 are synthesized coordinately in developing neurons (Shaw and Weber, 1982; Cochard and Paulin, 1984), but our observations suggest that the presence of these proteins in the P19-derived neurons was differentially controlled. However, in double-labeling experiments using the NF160 monoclonal antibody and an NF68 rabbit polyclonal antiserum (Julien and Mushynski, 1983), the majority of neuronal processes that contained one neurofilament protein also contained the other (Fig. 3). It seems likely, therefore, that the differential detection of NF68 and NF160 may have more to do with the cpitope being detcetcd than the presence or absence of the protein. It is known that neurofilament proteins are phosphorylated (Julien and Mushynski, 1982) and that the NF68 and NF160 monoclonal antibodies may react with sites on the neurofilament proteins that are subject to posttranslational modifications.

Synaptophysin is an integral membrane protein present in the presynaptic membranes of neurons (Wiedenmann and Franke, 1985). The monoclonal antibody SY38 reacts with synapto- physin and stained many but not all cells with neuronal morphology with a punctate pattern (Fig. 1,e,f).

Markers for neuronal subsets. Neurons are usually classified on the basis of the neurotransmitters that they synthesize and to which they respond: Our earlier observations indicated the presence of CAT and AChE in RA-treated P19 cultures (JonesVilleneuve et al., 1983), suggesting that at least some of the neurons were cholinergic. To determine whether these neurons do indeed synthesize and store $\mathrm{ACh}$, cultures were incubated in the presence of ${ }^{3} \mathrm{H}$-choline $(1 \mu \mathrm{Ci} / \mathrm{ml}, 80 \mathrm{Ci} / \mathrm{mmol})$ for $2 \mathrm{hr}$ in choline-free medium. The cultures were then washed, the cells sonicated, and the extract analzyed by HPLC for the presence of ${ }^{3} \mathrm{H}-\mathrm{ACh}$.

A very small amount of ${ }^{3} \mathrm{H}-\mathrm{ACh}$ was detected in cultures of undiffcrentiated P19. cells, but this level increased dramatically following RA treatment (Fig. 4). Although we have not demonstrated it directly, it seems likely that the CAT and ${ }^{3} \mathrm{H}-\mathrm{ACh}$ synthesis occurs within neurons and not in glial or fibroblastlike cells in these RA-treated cultures.

NGF has been shown to increase the level of CAT in some central and peripheral nervous system neurons in vivo (Korsching, 1986). Addition of NGF to neuron-containing P19 cultures did not result in increased ${ }^{3} \mathrm{H}-\mathrm{ACh}$ synthesis (data not shown). 


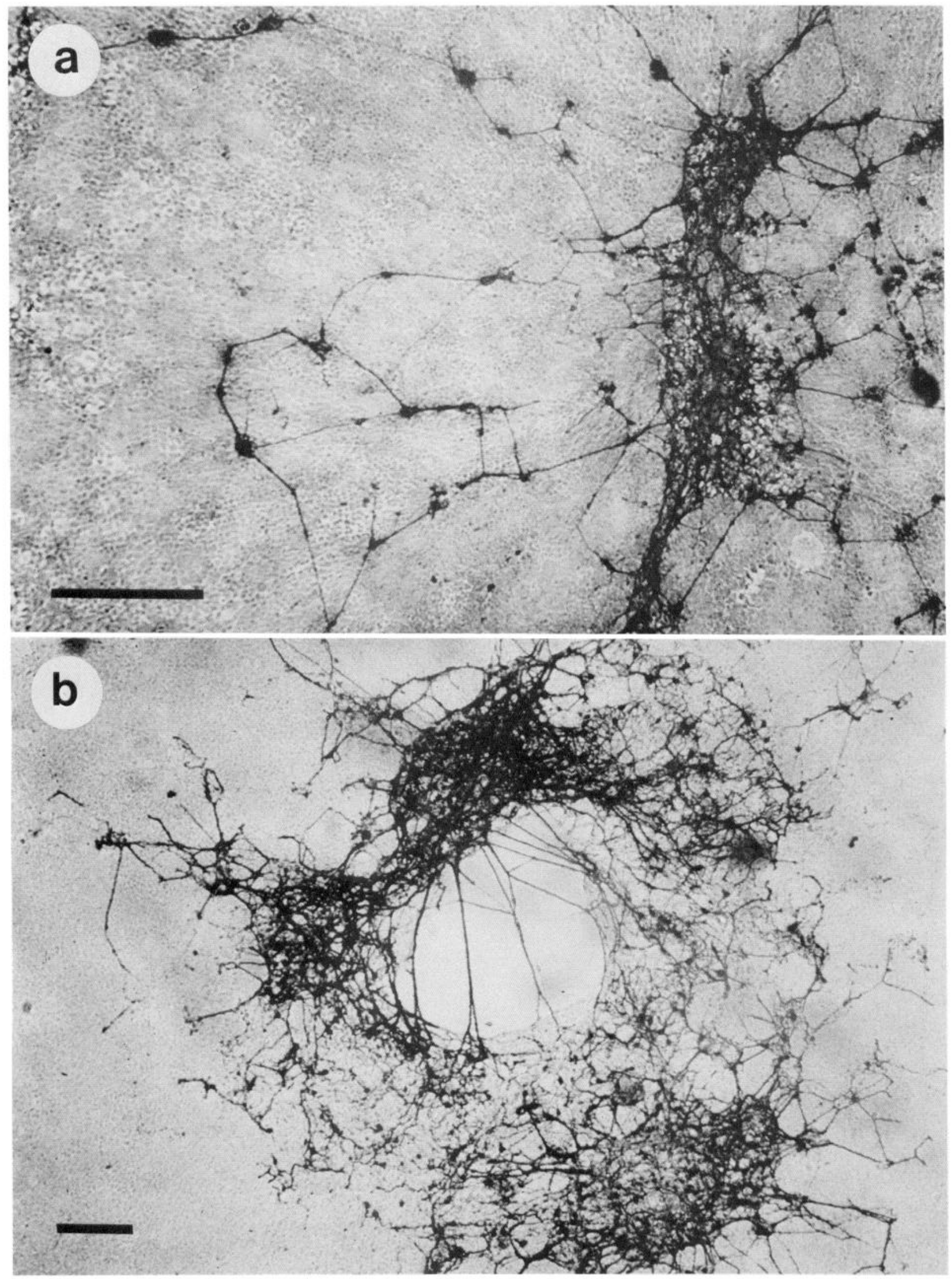

Figure 5. P19-derived neurons have high-affinity uptake sites for GABA. RA-treated cultures of P19 cells were incubated for $11 \mathrm{~d}$ before being washed with PBS and incubated for $2 \mathrm{hr}$ in ${ }^{3} \mathrm{H}-\mathrm{GABA}(2 \mu \mathrm{Ci} / \mathrm{ml}, 80 \mathrm{Ci} / \mathrm{mmol})$ in regular growth medium $(a)$ or growth medium containing $1 \mathrm{~mm}$ beta-alanine $(b)$. Cultures were then washed extensively with PBS, fixed in glutaraldehyde, and prepared for autoradiography. Magnification bars, $50 \mu \mathrm{m}$. 
This may not necessarily indicate that the P19-derived neurons are not responsive to NGF, because NGF may be continually present in these RA-treated cultures. Differentiated derivatives of EC cells have been shown to synthesize and secrete NGF (Dicou et al., 1986).

Since RA-treated cultures of P19 cells may contain different kinds of neurons that synthesize different neurotransmitters, and since some ncurons may synthesize a variety of neurotransmitters (Chan-Palay et al., 1982), we examined RA-treated P19 cultures for synthesis of other neurotransmitters. Using an electrochemical detection system, we failed to detect any of the catecholamines (norepinephrine, epinephrine, dopamine, or 5-HT) in P19-derived cultures. To increase the sensitivity of the detection system, differentiated cultures were incubated for 2 $\mathrm{hr}$ in tyrosine-free medium supplemented with ${ }^{3} \mathrm{H}$-tyrosine (2 $\mu \mathrm{Ci} / \mathrm{ml}, 15 \mathrm{Ci} / \mathrm{mmol}$ ), the amino acid precursor of catecholamines. Cell extracts again failed to yield detectable levels of radioactivity associated with any of the catecholamine peaks.

To determine whether P19-derived cultures synthesized GABA, an inhibitory neurotransmitter, cell extracts were assayed for glutamic acid decarboxylase (GAD) activity by Dr. David Gottlieb (Washington University Medical School, St. Louis, MO) using a sensitive radiochemical method (Gottlieb et al., 1986). No activity was detected even in cultures maintained for $10 \mathrm{~d}$ following RA treatment. To determine whether a subpopulation of neurons might contain GAD, we performed immunofluorescence experiments using the monoclonal antibody GAD-1, reactive with the rodent enzyme (Gottlieb et al., 1986). No immunoreactivity was detected.

Neurons that are responsive to a particular neurotransmitter generally have high-affinity receptors for that neurotransmitter on their cell surface. We used ${ }^{3} \mathrm{H}-5-\mathrm{HT}$ and ${ }^{3} \mathrm{H}-\mathrm{GABA}$ (New England Nuclear) and the procedures of Yamamoto et al. (1981) to look for neurons in RA-treated P19 cultures with such highaffinity receptors. No specific ${ }^{3} \mathrm{H}-5-\mathrm{HT}$ uptake was detected, but ${ }^{3} \mathrm{H}-\mathrm{GABA}$ was specifically accumulated in cells with neuronal processes (Fig. 5). This ${ }^{3} \mathrm{H}-\mathrm{GABA}$ uptake was not affected by 1 mM beta-alanine, an amino acid that inhibits uptake of GABA via nonspecific uptake systems.

Cells with high-affinity GABA uptake were evident by $5 \mathrm{~d}$ after initiation of RA treatment. The intensity of labeling with ${ }^{3} \mathrm{H}-\mathrm{GABA}$ was somewhat variable from cell to cell and increased from day 5 to day 10, probably as a consequence of increasing numbers of high-affinity sites per cell. The shapes of the cells labeled with ${ }^{3} \mathrm{H}-\mathrm{GABA}$, the time of the appearance of cells with this uptake system, and the absence of an effect of beta-alanine strongly suggest that the labeled cclls wcre ncurons and not the glial cell precursors that can have high-affinity GABA receptors (Levi et al., 1986). It appeared that all cells with processes were labeled with ${ }^{3} \mathrm{H}-\mathrm{GABA}$ and that the variable intensities were probably a consequence of developmental asynchrony.

Ultrastructure of maturing neurons. The first neuron-specific markers became evident in RA-treated P19 cultures on day 3, but electron microscopy of cells at this stage did not reveal any neuronal characteristics (Fig. 6A). The cells were tightly packed within the aggregates, with little apparent extracellular space. The individual cells were small, with round to oval nuclei containing a modest amount of heterochromatin. The cytoplasm contained numerous mitochondria and short segments of rough endoplasmic reticulum. By days 4 and 5 (Fig. 6, B, C), after aggregation and RA treatment, necrotic cells were observed. Viable cells adjacent to the degenerating zones were usually round or spindle-shaped, with bland, oval nuclei and prominent nucleoli. The cytoplasm of these cells contained many polyribosomes, clusters of mitochondria, and a few lipid droplets. Elongated cytoplasmic processes were identified at day 5. These structures contained well-ordered microtubules and resembled early neurites observed in developing nerve cells.

Unambiguous neuronal differentiation was seen by day 9 (Fig. $6 D$ ). Numerous neuritic processes coursed between the cells, whose cytoplasm contained an abundant complement of organelles with the Golgi apparatus particularly well-developed. The endoplasmic reticulum consisted of short cisternal segments filled with an amorphous, proteinaceous material.

Aggregates incubated for longer periods contained obvious neuronal areas composed of interdigitated neurites in which both axons and dendrites could be distinguished. Synapses were abundant (Fig. 7). These synapses had pre- and postsynaptic densities along with presynaptic vesicles. The round, hollow morphology of the presynaptic vesicles was similar to those normally characteristic of excitory junctions (Uchizono, 1969; Valdivia, 1971).

Astrocytes containing bundles of glial flaments were interspersed with the neuronal elements. No myelination of the neuronal processes and no examples of cells with oligodendrocyte characteristics were observed. Consistent with the absence of oligodendrocytes was our failure to find cells reactive with antibody directed against galactocerebroside (data not shown).

\section{Discussion}

RA-treated P19 cultures develop into neurons, astroglia, and fibroblast-like cells (Jones-Villeneuve et al., 1982). The neurons in thesc cultures have high-affinity uptake sites for the inhibitory neurotransmitter GABA, and synthesize the excitatory neurotransmitter $\mathrm{ACh}$. We have not yet investigated whether these neurons respond to extracellular signals by changing any aspect of their character, such as neurotransmitter synthesis, but it is clear that differentiation of neuronal processes into axons and dendrites does occur and that synapses do form between axons and dendrites.

The P19-derived neurons appeared to mature with incubation in culture. The amounts of ${ }^{3} \mathrm{H}$-ACh synthesized and ${ }^{3} \mathrm{H}-\mathrm{GABA}$ accumulated in neurons increased over the period from 5 to 10 $\mathrm{d}$ after RA treatment, and electron microscopy indicated progressively increasing amounts of neurite development, culminating in the formation of increasing numbers of synapses.

Cultures of RA-treated P19 cells contain CAT activity (JonesVilleneuve et al., 1983) and synthesize and store ACh. Although Parnavelas et al. (1985) have shown that CAT is present in some vascular endothelial cells, it seems very likely that the CAT in $\mathrm{P} 19$ cultures is present within the neuronal cells, rather than in some other cell type. We lack direct evidence for the cholinergic nature of the neurons; however, the presynaptic vesicles observed in the electron microscope were always round and hollow, consistent with use of $\mathrm{ACh}$ as the neurotransmitter.

The HNK-1 monoclonal antibody is a valuable marker for identification of neurons in RA-treated P19 cell cultures. Virtually all cells with neuronal-like processes stained with HNK-1, and the antigen recognized by HNK-1 first appeared on day 3 along with the neurofilament proteins. The epitope recognized by HNK-1 is a carbohydrate (Kruse et al., 1984) that may be involved in cell adhesion. It may be relevant to note that the neurons and glial cells in RA-treated P19 cultures are always found together (with the neurons usually lying on top of the glial 

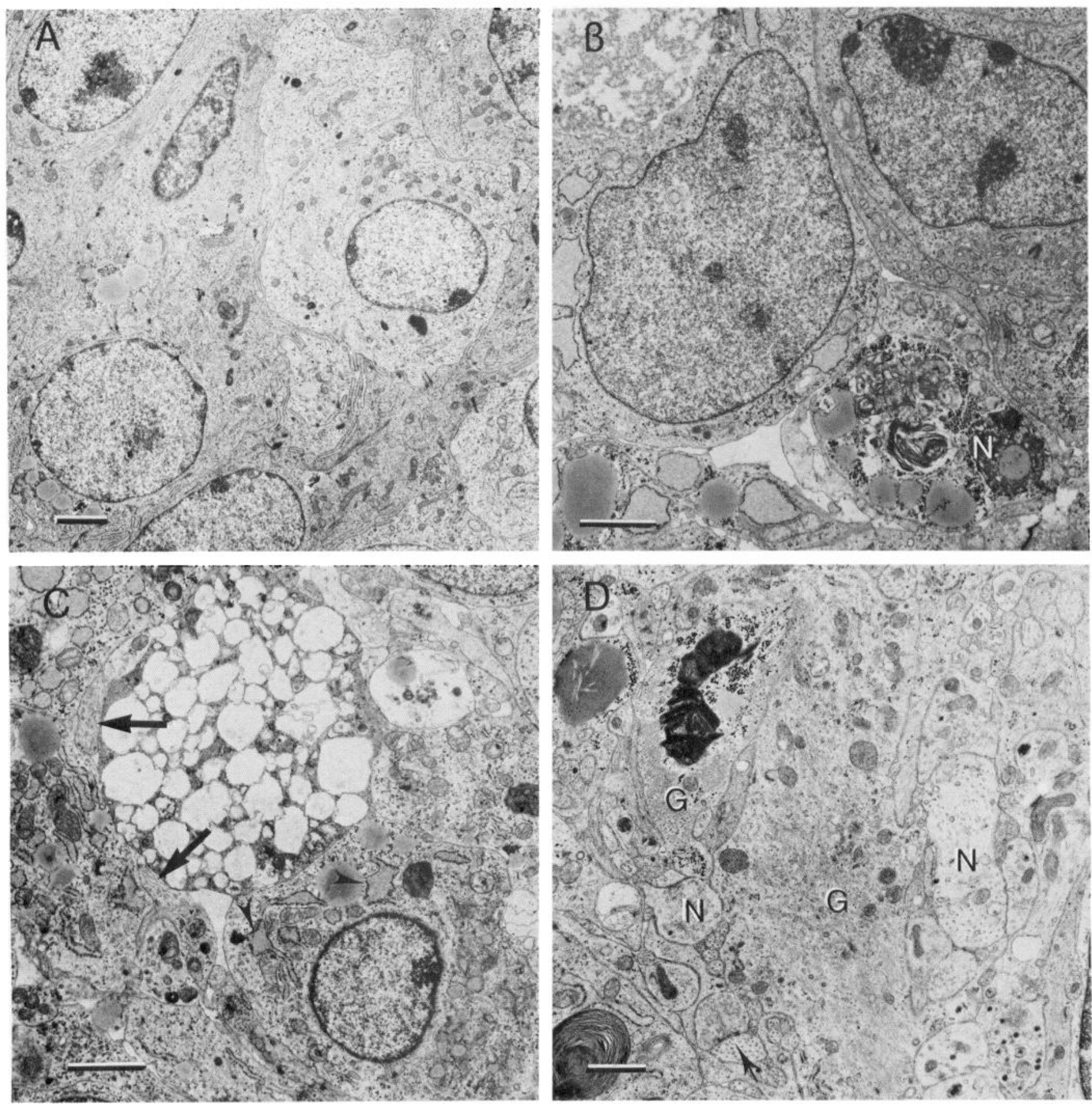

Figure 6. RA-treated aggregates of P19 cells develop gradually into neural tissue. RA-treated aggregates maintained for $3 \mathrm{~d}(A)$ contain only tightly packed cells with characteristics of undifferentiated cells: few organelles and no neural characteristics. By day $4(B)$, necrotic areas $(N)$ become evident, but there remains little change in the appearance of the surviving cells. Cell processes containing microtubules and microfilaments were evident on day 5 (arrows in $C$ ) in cells containing more extensive endoplasmic reticulum (ER). Some cells contained ER distended with amorphous electron-dense material (arrowheads in $C$ ). After $9 \mathrm{~d}(D)$, glial $(G)$ and neuronal $(N)$ processes were frequent. The glial processes contained bundles of filaments (probably glial fibrillary acid protein-intermediate filaments) and neurites were distinguishable as either axons or dendrites. Some synapses (arrow) were also present. Magnification bars, $2 \mu \mathrm{m}$.

cell monolayer), while the fibroblast-like cells are seldom covered with neurons.

The A2B5 antibody appears less reliable and valuable as a marker for neurons, since some non-neuronal cells stained with this monoclonal antibody in both EC and differentiated cell populations. The A2B5-positive cells in EC cultures may represent cells precommitted to the neuronal lineage. This possi- bility will be investigated further, but seems unlikely in view of the presence of A2B5 antigen on non-neuronal cells in differentiated cell cultures, its presence on some cell lines derived from the fibroblast-like cells (Bell et al., 1986), and its presence on about $5 \%$ of the cells in cultures of the F9 line (data not shown), an EC cell incapable of differentiating into the neuronal lineage (Tienari et al., 1987). 



Figure 7. RA-treated P19 cell aggregates incubated for extended periods develop axons, dendrites, and synapses. Aggregates were incubated for $15 \mathrm{~d}$ following exposure to RA before being fixed and prepared for electron microscopy. Processes of astrocytes containing glial fibrils $(A$, asterisks) were present throughout the aggregates. Axons $(A)$ containing round vesicles were also frequently noted. Well-developed axodendritic synapses $(B)$ were common. In some areas of the aggregates $(C, D)$, single or multiple axons synapsed with a single dendrite (arrows), while glial processes (asterisks) interdigitated between the neuritic processes. Magnification bar: $1(A, C, D), 0.5 \mu \mathrm{m}(B)$.

Synaptophysin was apparently present in many, but not all, neuronal processes of RA-treated P19 cells. The absence of synaptophysin from many processes may indicate (1) that its appearance is asynchronous and a relatively late event in neuronal cell maturation, (2) that only a subset of all neurons is capable of synthesizing synaptophysin, or (3) that this protein is located only in those neuronal processes destined to become axons. In any event, the presence of synaptophysin is consistent with the electron-microscopic appearance of synapses but its value as a neuronal marker in this system will be limited by the absence of early expression in all neurons.

The biological system described above, along with the HNK-1 marker, should prove to be a valuable one with which to investigate the development of cholinergic neurons from pluripotential precursor cells, the subsequent maturation of these neurons in vitro, culminating in the development of synaptic junctions, and the relationship between neurons and glial cells, which always appear in these cultures together. 


\section{References}

Abo, T., and C. M. Balch (1981) A differentiation antigen of human NK and $\mathrm{K}$ cells identified by a monoclonal antibody (HNK-1). J. Immunol. 127: 1024-1029.

Ally, A. I., L. Vieira, and K. R. Reuhl (1986) Trimethyltin as a selective adrenal chemosympatholytic agent in vivo: Effect precedes both clinical and histopathological evidence of toxicity. Toxicology 40:215229.

Bell, J. C., K. Jardine, and M. W. McBurney (1986) Lineage-specific transformation after differentiation of multipotential murine stem cells containing a human oncogene. Mol. Cell. Biol. 6: 617-625.

Bymaster, F. P., K. W. Perry, and D. T. Wong (1985) Measurement of acetylcholine and choline in brain by HPLC with electrochemical detection. Life Sci. 37: 1775-1781.

Chan-Palay, V., A. G. Engel, J. Y. Wu, and S. L. Palay (1982) Coexistence in human and primate neuromuscular junctions of enzymes synthesizing acetylcholine, catecholamine, taurine, and gamma-aminobutyric acid. Proc. Natl. Acad. Sci. USA 79: 7029-7030.

Cochard, P., and D. Paulin (1984) Initial expression of neurofilaments and vimentin in the central and peripheral nervous system of the mouse embryo in vivo. J. Neurosci. 4: 2080-2094.

Coulombe, J. N., and M. Bronner-Fraser (1986) Cholinergic neurons acquire adrenergic neurotransmitters when transplanted into an embryo. Nature 324: 569-572.

Dicou, E., R. Houlgatte, and P. J. Brachet (1986) Synthesis and secretion of beta-nerve growth factor by mouse teratocarcinoma cell lines. Exp. Cell Res. 167: 287-294.

Edwards, M. K. S., J. F. Harris, and M. W. McBurney (1983) Induced muscle differentiation in an embryonal carcinoma cell line. Mol. Cell. Biol. 3: 2280-2286.

Eisenbarth, G. S., F. S. Walsh, and M. Nirenberg (1979) Monoclonal antibody to a plasma membrane antigen of neurons. Proc. Natl. Acad. Sci. USA 76: 4913-4917.

Eisenbarth, G. S., K. Shimizu, M. A. Bowring, and S. Wells (1982) Expression of receptors for tetanus toxin and monoclonal antibody A2B5 by pancreatic islet cells. Proc. Natl. Acad. Sci. USA 79: 50665070.

Gottlieb, D. I., Y. C. Chang, and J. E. Schwab (1986) Monoclonal antibodics to glutamic acid dccarboxylasc. Proc. Natl. Acad. Sci. USA 83: $8808-8812$.

Jacobson, M. (1985) Clonal analysis and cell lineages of the vertebrate central nervous system. Annu. Rev. Neurosci. 8: 71-102.

Jones-Villeneuve, E. M. V., M. W. McBurney, K. A. Rogers, and V. I. Kalnins (1982) Retinoic acid induces embryonal carcinoma cells to differentiate into neurons and glial cells. J. Cell Biol. 94: 253-262.

Jones-Villeneuve, E. M. V., M. A. Rudnicki, J. F. Harris, and M. W. McBurney (1983) Retinoic acid-induced neural differentiation of embryonal carcinoma cells. Mol. Cell. Biol. 3: 2271-2279.

Julien, J. P., and W. E. Mushynski (1982) Multiple phosphorylation sites in mammalian neurofilament polypeptides. J. Biol. Chem. 257: 10467-10470.

Julien, J. P., and W. E. Mushynski (1983) The distribution of phosphorylation sites among identificd protcolytic fragments of mammalian neurofilaments. J. Biol. Chem. 258: 4019-4025.

Kasai, N., and R. K. Yu (1983) The monoclonal antibody A2B5 is specific to ganglioside GQ1c. Brain Res. 277: 155-158.

Korsching, S. (1986) The role of nerve growth factor in the CNS. Trends Neurosci. 9: 570-573.

Kruse, J., R. Mailhammer, H. Wernecke, A. Faissner, I. Sommer, C. Goridis, and M. Schachner (1984) Neural cell adhesion molecules and myelin-associated glycoprotein share a common carbohydrate moiety recognized by monoclonal antibodies $\mathrm{L} 2$ and HNK-1. Nature 311: 153-155.

Levi, G., V. Gallo, and M. T. Ciotti (1986) Bipotential precursors of putative fibrous astrocytes and oligodendrocytes in rat cerebellar cultures express distinct surface features and "neuron-like" gamma-aminobutyric acid transport. Proc. Natl. Acad. Sci. US $\Lambda$ 83: 1504-1508.

Levine, J. M., and P. Flynn (1986) Cell surface changes accompanying the neural differentiation of an embryonal carcinoma cell line. $\mathbf{J}$. Neurosci. 6: 3374-3384.

Lynch, S. A., J. S. Brugge, and J. M. Levine (1986) Induction of an altered $c$-src gene product during neural differentiation of an embryonal carcinoma cell line. Science 234: 873-876.

McBurney, M. W., and B. J. Rogers (1982) Isolation of male embryonal carcinoma cells and their chromosome replication patterns. Dev. Biol. 89: 503-508.

McBurney, M. W., and E. M. V. Jones-Villenueve, M. K. S. Edwards, and P. J. Anderson (1982) Control of muscle and neuronal differentiation in a cultured embryonal carcinoma cell line. Nature 299: 165-167.

McGarry, R. C., S. L. Helfand, R. H. Quarles, and J. C. Roder (1983) Recognition of myelin-associated glycoprotein by the monoclonal antibody HNK-1. Nature 306: 376-378.

Papaioannou, V. E. (1979) Interactions between mouse embryos and teratocarcinomas. INSERM Symp. 10: 141-155.

Park, J. K., T. H. Joh, and F. F. Ebner (1986) Tyrosine hydroxylase is expressed by neocortical neurons after transplantation. Proc. Natl. Acad. Sci. USA 83: 7495-7498.

Parnavelas, J. G., W. Kelley, and G. Burnstock (1985) Ultrastructural localization of choline acetyltransferase in vascular endothelial cells in rat brain. Nature 316: 724-725.

Patterson, P. H. (1978) Environmental determination of autonomic neurotransmitter functions. Annu. Rev. Neurosci. 1: 1-17.

Raff, M. C., R. H. Miller, and M. Noble (1983) A glial progenitor cell that develops in vitro into an astrocyte or an oligodendrocyte depending on culture medium. Nature 303: 390-396.

Rudnicki, M. A., and M. W. McBurney (1987) Cell culture methods and induction of differentiation of embryonal carcinoma cell lines. In Teratocarcinoma and Embryonic Stem Cells. A Practical Approach, E. J. Robertson, ed., pp. 19-50, IRL Press.

Schnitzer, J., and M. Schachner (1982) Cell type specificity of a neural cell surface antigen recognized by the monoclonal antibody A2B5. Cell Tissue Res. 224: 625-636.

Schuller-Petrovic, S., W. Gebhart, H. Lassman, H. Rumpold, and D. Kraft (1983) A shared antigenic determinant between natural killer cells and nervous tissue. Nature 306: 179-181.

Shaw, G., and K. Weber (1982) Differential expression of neurofilament triplet proteins in brain development. Nature 298: 277-279.

Solter, D., and B. B. Knowles (1978) Monoclonal antibody defining a stage-specific mouse embryonic antigen (SSEA-1). Proc. Natl. Acad. Sci. USA 75: 5565-5569.

Tapscott, S. J., G. S. Bennett, and H. Holtzer (1981) Neuronal precursor cells in the chick neural tube express neurofilament proteins. Nature 292: 836-838.

Tienari, J., I. Virtanen, S. Soinila, and E. Lehtonen (1987) Neuronlooking derivatives of cultured F9 embryonal carcinoma cells express characteristics of parietal endoderm cells. Dev. Biol. (in press).

Tucker, G. C., H. Aoyama, M. Lipinski, T. Tursz, and J. P. Thiery (1984) Identical reactivity of monoclonal antibodies HNK-1 and NC-1: Conservation in vertebrates on cells derived from the neural primordium and on some leukocytes. Cell Differ. 14: 223-230.

Uchizono, K. (1969) Synaptic organization of the mammalian brain. In Neurobiology of Cerebellar Evolution and Development, R. Llinas, ed., pp. 549-581, Chicago AMA-ERF Institute for Biomedical Research, Chicago.

Valdivia, O. (1971) Methods of fixation and the morphology of synaptic vesicles. J. Comp. Neurol. 142: 257-277.

Vincent, M., and J. P. Thiery (1984) A cell surface marker for neural crest and placodal cells: Further evolution in peripheral and central nervous system. Dev. Biol. 103: 468-481.

Wiedenmann, B., and W. W. Franke (1985) Identification and localization of synaptophysin, an integral membrane glycoprotein of $\mathrm{Mr}$ 38,000 characteristic of presynaptic vesicles. Cell 41: 1017-1028.

Yamamoto, M., H. M. Steinbusch, and T. M. Jessel (1981) Differentiated properties of identified serotonin neurons in dissociated cultures of embryonic rat brain stem. J. Cell Biol. 91: 142-152. 